\title{
THE USUAL EXCESS-BURDEN APPROXIMATION USUALLY DOESN'T COME CLOSE
}

\author{
Lawrence H. Goulder \\ Roberton C. Williams III \\ Working Paper 7034 \\ http://www.nber.org/papers/w7034
NATIONAL BUREAU OF ECONOMIC RESEARCH
1050 Massachusetts Avenue
Cambridge, MA 02138
March 1999

We are grateful to Lans Bovenberg, Lars Hakonsen, Jim Hines, Ken Judd, Gib Metcalf, Bill Nordhaus, Ian Parry, and John Whalley for very helpful comments on an earlier version of this paper. The views expressed in this paper are those of the authors and do not reflect those of the National Bureau of Economic Research.

(C) 1999 by Lawrence H. Goulder and Roberton C. Williams III. All rights reserved. Short sections of text, not to exceed two paragraphs, may be quoted without explicit permission provided that full credit, including (C) notice, is given to the source. 
The Usual Excess-Burden Approximation

Usually Doesn't Come Close

Lawrence H. Goulder and Roberton C. Williams III

NBER Working Paper No. 7034

March 1999

JEL No. H21, D61

\section{ABSTRACT}

This paper shows that the usual "excess-burden triangle" formula performs poorly when used to assess the excess burden from taxes on intermediate inputs or consumer goods, and derives a practical alternative to this formula. We use an analytically tractable general equilibrium model to reveal how interactions with pre-existing taxes in other markets critically affect the excess burden of new taxes on intermediate inputs or consumer goods. The usual excess-burden formula ignores these interactions, and consequently yields highly inaccurate assessments of excess burden.

Prior economic theory implicitly acknowledges the relevance of general-equilibrium interactions to excess burden, but does not indicate which interactions are most important or reveal the fundamental (first-order) contribution of these interactions. Moreover, prior studies do not offer a practical alternative to the usual excess-burden approximation. This paper helps fill the gap between theory and practice. First, it shows analytically that the importance of the interaction with a given pre-existing tax is roughly proportional to the amount of revenue raised by that tax. Second, the paper derives a practical alternative formula for approximating the excess burden from a commodity tax. Finally, it performs numerical simulations to illustrate the significance of adopting our alternative to the usual approximation formula. For realistic parameter values and a wide range of assumed rates for prior taxes, the usual formula captures less than half of the excess burden of taxes on commodities. When the rate of the new tax is "small," this formula captures less than five percent of the true excess burden. In contrast, the alternative approximation formula derived here yields estimates that are consistently within five percent of the actual excess burden.

Lawrence H. Goulder Department of Economics Landau Economics Building Stanford University Stanford, CA 94305-6072 and NBER goulder@leland.stanford.edu
Roberton C. Williams III Department of Economics Landau Economics Building Stanford University Stanford, CA 94305-6072 robwilli@leland.stanford.edu 


\section{Introduction}

By driving a wedge between marginal benefit and marginal cost, taxes tend to generate distortionary costs or excess burden. Assessing this burden is a key aspect of evaluating any proposed new tax. To gauge the excess burden, economists frequently invoke the excess-burden (or "Harberger") triangle. The area of this triangle (and thus the implied excess burden) is $1 / 2 t \Delta q$, where $t$ is the rate of the newly imposed tax in a given market and $\Delta q$ is the change in equilibrium quantity in that market. The area of the triangle can be expressed in terms of slopes of supply and demand curves. In the case where the taxed good is supplied perfectly elastically, the area is simply $1 / 2(1 / b) t^{2}$, where $b$ is the negative of the slope of the demand curve in the relevant range and $t$ is the tax rate (Figure 1a). When the elasticity of supply is less than infinite, the area is $1 / 2[1 /(b+c)] t^{2}$, where $c$ is the slope of the supply curve over the relevant range (Figure 1b). These simple expressions offer important insights, such as the idea that the excess burden in the taxed market rises more than in proportion with the tax rate, or the notion that the excess burden tends to be larger, the more elastic is supply or demand. ${ }^{1}$

Despite its intuitive appeal, the excess-burden triangle often yields a very poor approximation of excess burden. For important types of taxes - namely, taxes on intermediate inputs such as fuels or raw materials, and taxes on consumer goods such as gasoline, tobacco, or jewelry - this usual excess-burden approximation may seriously miss the mark, even by orders of magnitude.

The fundamental difficulty with the usual formula, which accounts for its poor performance, is that it disregards interactions between the market for the taxed commodity ${ }^{2}$ and markets for other goods subject to distortionary taxes. These interactions can significantly influence the deadweight loss from a given tax. As we show here, factor-market interactions are particularly important: intermediate- or consumer-good taxes function as implicit increases in factor taxes, augmenting whatever distortions are already present in factor markets. To the extent that the prior distortions in factor markets - resulting, for example, from prior factor taxes like personal or corporate income taxes - are substantial, the additional distortion (excess burden) generated in factor markets can be quite large. In fact, for realistic values of prior factor-tax rates, the additional factor-market distortions imposed by intermediate- or consumer-good taxes can be many times larger than the "direct" distortions considered by the excess-burden triangle. In measuring the excess burden from goods taxes, these interactions are of first-order importance.

\footnotetext{
${ }^{1}$ Auerbach (1985) provides a general discussion of the concept and measurement of excess burden. Hines (1999) offers a recent survey of the history and use of the Harberger triangle to measure deadweight losses.

2 We use the term "commodity" to refer to any produced (intermediate or consumer) good.
} 
Prior theory recognizes that such interactions exist and that they will influence the deadweight loss from taxation. For example, Harberger (1964b) generalizes the simplest excess-burden formula, offering an expression in which the excess burden of a new tax is the sum, over all markets, of the product of the prior tax rate in each market times the change in quantity in that market caused by the imposition of the new tax. In a different vein, the literature on optimal taxation, including the important contributions of Diamond and Mirrlees (1971) and Atkinson and Stiglitz (1972), implicitly recognizes the importance of interactions between taxes in different markets. For example, Diamond and Mirrlees showed that in the absence of externalities, the optimal tax system will not involve taxes on intermediate inputs. This result reflects the interaction between intermediate input and consumer good taxes. For if there were no interactions between markets, the most efficient way to raise a given amount of revenue would be to introduce at least a small tax in every market, including the market for each intermediate good. This clearly would contradict Diamond and Mirrlees's result. Thus, a basis for Diamond and Mirrlees's result is that intermediate input taxes interact with other taxes, distorting individuals' choices among consumer goods. ${ }^{3}$

Notwithstanding these fundamental contributions, there remains a large gap between theory and the practical assessment of excess burden. Although prior theory indicates that prior distortions in other markets can affect the excess burden of a new tax, it offers no clues about which other market distortions are likely to be most important. Nor does it reveal how much of the overall excess burden from a given new tax will derive from distortions in other markets, and how much will stem from the market in which the new tax is imposed. Thus it does not make clear the extent of the errors involved when one uses the simplest excess-burden-triangle formula. Finally, the theory leaves applied economists without a practical alternative to the usual excess-burden formula.

Perhaps because the weaknesses of the usual formula have not been made clear, or because of the lack of practical alternatives, economists routinely apply the usual approximation formula to assess the excess burden from commodity taxes, even though it leads to highly inaccurate results. Faced with uncertainties about the significance (and even the sign) of the effect of pre-existing distortions in other markets, many economists have disregarded these issues, implicitly assuming the overall impact of the

\footnotetext{
${ }^{3}$ Another related literature connects optimal tax results with excess burden, addressing the welfare effects of incremental changes in the tax system from arbitrary starting points. The bulk of this literature focuses on negative results. For example, Boadway and Harris (1977) show that a small move towards the optimum can yield either a welfare loss or gain. Dixit (1975) is perhaps the most notable exception, showing a number of conditions under which a marginal tax reform will yield a welfare gain. This literature does not explicitly calculate the excess burden of individual taxes; rather, it emphasizes sufficient conditions under which changing a particular tax or set of taxes will lead to a welfare gain. Furthermore, while these conditions are in some cases quite general, they do not correspond well to situations that real-world tax authorities may face. Hence this literature does not offer a practical method for measuring the excess burdens from consumer and intermediate good taxes.
} 
other distortions is zero. Even some of the most eminent empirical economists have been led astray because of the need to use the usual formula.

This paper aims to fill the gap between theory and practice. First, it extends prior theory by indicating which other markets will be most important in contributing to the overall excess burden of a new commodity (intermediate input or final good) tax. Specifically, we show that the relative importance of other markets to the excess burden of a new commodity tax is largely determined by the amount of revenue raised by the prior taxes in other markets. In the U.S. and many other countries, where most government revenue is generated by factor taxes, the distortions from pre-existing taxes of this type are the most important. Second, the paper offers an empirically implementable formula for evaluating the excess burden from a commodity tax, thus providing an alternative to the simple excess-burden-triangle formula. Finally, it performs numerical simulations to illustrate the significance of adopting our alternative to the usual formula. Our numerical results indicate that the alternative formulas derived in this paper are typically far more accurate - even by orders of magnitude - than the usual excess-burden formula. This is true even when prior taxes on factors are fairly low.

There are considerable uncertainties as to the values of parameters (in particular, cross-price elasticities) that influence the significance of the market interactions discussed here. In light of these uncertainties, some might regard the usual formula as a reasonable, simple starting point. This paper indicates that the usual formula is not a good starting point because it implicitly makes parameter assumptions that are far from neutral and that are biased toward underestimating the actual excess burden. In contrast, our alternative formula is unbiased in that it assumes the newly taxed commodity is "average" in relevant respects.

The next section develops the basic analytical general equilibrium model and applies that model to arrive at two alternative excess-burden formulas - one for intermediate input taxes, and one for consumer good taxes. Section III employs numerical simulations to examine the accuracy of the usual excess-burden formula and our alternative formulas. Section IV then extends the analytical model to consider a more general set of production relationships and to consider the implications of imperfect competition. The final section offers conclusions.

\section{The Model}

This section develops a simple general equilibrium model to derive formulas for the excess burden of taxes on consumer goods and intermediate goods. ${ }^{4}$

\footnotetext{
${ }^{4}$ The model and method of analysis here are similar in some respects to those used in previous studies of secondbest issues in environmental regulation (Parry, Williams, and Goulder, 1999) and in international trade (Williams,
} 


\section{A. Assumptions}

A representative agent model is assumed, where households divide their time endowment $(T)$ between leisure $(l)$ and labor $(L)$, which is the only primary factor of production. Households use their income to purchase each of $M$ consumer goods $\left(C_{1}, \ldots, C_{M}\right)$ in order to maximize the utility function

$$
U\left(l, C_{1}, \ldots, C_{M}\right)
$$

which is continuous and quasi-concave.

Labor is used to produce both consumer goods and $N$ different intermediate goods $\left(I_{1}, \ldots, I_{N}\right)$. Each consumer good is produced using labor and the intermediate goods as inputs, according to the production function

$$
C_{i}=F_{i}\left(L_{C i}, I_{i 1}, \ldots, I_{i N}\right)
$$

where $L_{C i}$ is the amount of labor and $I_{i j}$ is the amount of intermediate good $j$ used in production of consumer good $i$. All production functions are assumed to exhibit constant returns to scale. Intermediate goods are produced exclusively from labor, with units normalized such that one unit of labor input can produce one unit of any intermediate good. ${ }^{5}$ Thus, production of intermediate goods follows

$$
I_{j}=L_{l j}
$$

where $L_{I j}$ is the amount of labor used in production of intermediate good $j$. The amount of each intermediate good used in production of consumer goods must match the amount produced.

$$
I_{j}=\sum_{i=1}^{M} I_{i j}
$$

The household's time constraint is given by

$$
T=L+l=\sum_{i=1}^{M} L_{C i}+\sum_{j=1}^{N} L_{l j}+l
$$

The government provides a lump-sum transfer payment $G$ to the household, financed by a labor $\operatorname{tax}\left(\tau_{L}\right)$ and taxes on consumer goods $\left(\tau_{C i}\right)$ and intermediate goods $\left(\tau_{I j}\right){ }^{6}$ After normalizing the pre-tax wage to unity, we can write the government budget constraint as

1998a). This model is distinct, however, in that it (1) disregards environmental externalities and international trade, (2) allows for pre-existing commodity taxes in addition to the pre-existing labor tax, and (3) considers (in Section III) a more general production function and the effects of imperfect competition.

5 In Section III, we extend this model to allow for the use of intermediate goods in the production of intermediate goods. This complicates the analysis somewhat, but the results remain unchanged for a tax on a typical good.

${ }^{6}$ As is well known, one of these $N+M+1$ taxes is redundant: the government can produce identical outcomes with various combinations of $N+M$ taxes. The intuition behind this paper's results is clearer, though, if we maintain this redundancy. 


$$
G=\tau_{L} L+\sum_{i=1}^{M} \tau_{C i} C_{i}+\sum_{j=1}^{N} \tau_{I j} I_{j}
$$

and the household budget constraint as

$$
\left(1-\tau_{L}\right)_{L}+G=\sum_{i=1}^{M} p_{C i} C_{i}
$$

where $p_{C i}$ is the price of consumer good $i$. The first-order conditions for firm profit-maximization give

$$
p_{C i}=\tau_{C i}+\frac{1}{\partial F_{i} / \partial L_{C i}}=\tau_{C i}+\frac{p_{i j}}{\partial F_{i} / \partial I_{i j}}
$$

where $p_{I j}$ is the price of intermediate good $j$, given by

$$
p_{l j}=\tau_{l j}+1
$$

Households maximize utility (1) subject to their time constraint (5) and budget constraint (7), taking government transfers, prices, the labor tax rate, and the environmental tax rate as given. This yields the first order conditions:

$$
U_{C i}=p_{C i} \lambda ; U_{l}=\left(1-\tau_{L}\right) \lambda
$$

where $\lambda$ represents the marginal utility of income. These first-order conditions, together with the other equations given thus far, implicitly define the Marshallian (uncompensated) demand functions:

$$
C_{i}\left(\tau_{C 1} \ldots \tau_{C M}, \tau_{I 1} \ldots \tau_{I N}, \tau_{L}\right) ; I_{j}\left(\tau_{C 1} \ldots \tau_{C M}, \tau_{I 1} \ldots \tau_{I N}, \tau_{L}\right) ; l\left(\tau_{C 1} \ldots \tau_{C M}, \tau_{I 1} \ldots \tau_{I N}, \tau_{L}\right)
$$

\section{B. Effects of a Tax on a Consumer Good}

Here we examine the effect of a tax on a single consumer good $k$. Totally differentiating utility with respect to $\tau_{c k}$, substituting in the consumer first-order conditions, and dividing through by $\lambda$ yield

$$
\frac{1}{\lambda} \frac{d U}{d \tau_{c k}}=\sum_{i=1}^{M} p_{c i} \frac{d C_{i}}{d \tau_{c k}}+\left(1-\tau_{L}\right) \frac{d l}{d \tau_{c k}}
$$

Totally differentiating the production equation for each consumer good with respect to $\tau_{c k}$ and substituting in the equations for consumer good prices (8) and intermediate goods prices (9) give

$$
\left(p_{C i}-\tau_{C i}\right) \frac{d C_{i}}{d \tau_{C k}}=\frac{d L_{C i}}{d \tau_{C k}}+\sum_{j=1}^{N} p_{l j} \frac{d I_{i j}}{d \tau_{c k}}
$$

Totally differentiating the household time constraint with respect to $\tau_{c k}$ gives

$$
0=\frac{d l}{d \tau_{C k}}+\sum_{i=1}^{M} \frac{d L_{C i}}{d \tau_{C k}}+\sum_{j=1}^{N} \frac{d L_{l j}}{d \tau_{C k}}
$$

Subtracting (14) from (12), substituting in (13) and canceling terms yield

$$
\frac{1}{\lambda} \frac{d U}{d \tau_{C k}}=\underbrace{\tau_{C k} \frac{d C_{k}}{d \tau_{C k}}}_{d W^{P}}+\underbrace{\sum_{i \neq k} \tau_{C i} \frac{d C_{i}}{d \tau_{C k}}+\sum_{j=1}^{N} \tau_{I j} \frac{d I_{j}}{d \tau_{C k}}-\tau_{L} \frac{d l}{d \tau_{C k}}}_{d W^{I}}
$$


This expression divides the welfare effect into two components: the primary welfare effect $\left(d W^{P}\right)$ and the tax-interaction effect $\left(d W^{I}\right){ }^{7} \quad$ The primary welfare effect is the impact of the tax $\tau_{c k}$ on the market for good $k$. This is the effect captured by the usual formula. It equals the tax rate times the change in consumption of good $k$. The tax-interaction effect is the impact of $\tau_{c k}$ on other tax-distorted markets. The first two terms within $d W^{I}$ are analogous to the primary welfare effect, except that they pertain to consumer goods other than good $k$ and to intermediate goods. The third term in $d W^{I}$ represents the impact on the labor market. Because the tax raises the price of $C_{k}$, it reduces the real wage, lowers the labor supply, and thereby exacerbates the labor-market distortion caused by the income tax. This causes a welfare loss equal to the change in labor supply times the distortionary wedge in the labor market.

Equation (15) is very similar to a general expression for excess burden obtained by Harberger (1964b). It differs only in the way it divides the economy's markets into the categories of labor, intermediate-input, and consumer-good markets. In its present form, this expression is not of much practical use: it would be difficult to obtain all of the partial derivatives that enter into the formula. However, by transforming this formula, we can get a sense as to which elements are likely to be most important, and this leads ultimately (in subsection D below) to an implementable approximation formula. Equation (15) can be expressed in terms of elasticities as

$$
\frac{1}{\lambda} \frac{d U}{d \tau_{C k}}=\underbrace{\frac{\tau_{C k} C_{k}}{p_{C k}} \varepsilon_{C k}}_{d W^{P}}+\underbrace{\sum_{i \neq k} \frac{\tau_{C i} C_{i}}{p_{C k}} \varepsilon_{C i C k}+\sum_{j=1}^{N} \frac{\tau_{l j} I_{j}}{p_{C k}} \varepsilon_{l i C k}-\frac{\tau_{\perp} L}{p_{C k}} \varepsilon_{L C k}}_{d W^{I}}
$$

where $\varepsilon_{C k}$ is the own-price elasticity of demand for consumer good $k, \varepsilon_{C i c k}$ is the cross-price elasticity for consumer good $i, \varepsilon_{I j C k}$ is the cross-price elasticity for intermediate good $j$, and $\varepsilon_{L C k}$ is the cross-price elasticity of labor supply, all with respect to the price of consumer good $k$.

The above expression suggests which terms in the tax-interaction effect are likely to be the most important. Each term in the tax-interaction effect is a cross-price elasticity term times the revenue from the tax in a particular market, divided by the price of good $k$. Thus, if the cross-price elasticities are all of roughly equal magnitude, the importance of the interaction term for a given market will be roughly proportional to the tax revenue raised in that market. Since the bulk of tax revenue in the United States and most industrialized nations is raised through factor taxes, factor-tax interactions seem likely to account for the bulk of the tax-interaction effect in these countries. Of course, if certain other goods are

\footnotetext{
${ }^{7}$ These effects have been defined and analyzed in prior literature examining the impacts, in a second-best setting, of environmental taxes (Parry (1995), Goulder et al. (1997), and Parry et al. (1999)) and of barriers to international trade (Williams (1998a)). These earlier studies incorporated environmental impacts and terms-of-trade effects (respectively) in the primary welfare effect. No such impacts occur in the model presented here.
} 
particularly strong substitutes for or complements to the taxed good, then the terms for those goods may be important as well.

We now define two concepts associated with the excess burden from the labor tax. These concepts will be useful in deriving an expanded expression for the tax-interaction effect and a practical expression for excess burden. First, we define

$$
\mu \equiv \frac{\tau_{L} \frac{\partial l^{c}}{\partial \tau_{L}}}{L-\tau_{L} \frac{\partial l}{\partial \tau_{L}}}
$$

where the superscript $C$ denotes a compensated derivative. This expression is the ratio of the marginal increase in deadweight loss in the labor market from a change in the labor tax rate to the marginal revenue raised by the labor tax, when the tax revenue is returned lump-sum to households. Thus, $\mu$ is the partialequilibrium marginal excess burden (MEB) of the labor tax. It is a partial-equilibrium concept because it ignores both the labor tax's effect on equilibrium quantities in other markets and the associated impacts on tax revenues in these other markets.

A corresponding definition applies in the case where marginal labor tax revenue is not returned to households: ${ }^{8}$

$$
\eta \equiv 1+\frac{\tau_{L} \frac{\partial l}{\partial \tau_{L}}}{L-\tau_{L} \frac{\partial l}{\partial \tau_{L}}}
$$

This is the partial-equilibrium marginal cost of public funds (MCPF) for the labor tax. In this case, the ratio of the marginal deadweight loss to the marginal revenue from the labor tax is similar, although the numerator depends on the uncompensated change in leisure demand, not the compensated change, because the marginal tax revenue is not returned. Households also lose the revenue raised, causing the MCPF to equal one plus the ratio of marginal deadweight loss to marginal revenue. ${ }^{9}$

Using these concepts, we can express the tax-interaction effect as (see Appendix A)

$$
d W^{I}=(\eta-1) \tau_{C k} \frac{d C_{k}}{d \tau_{C k}}+\eta \sum_{i \neq k} \tau_{C i} \frac{d C_{i}}{d \tau_{C k}}+\eta \sum_{j=1}^{N} \tau_{l j} \frac{d I_{j}}{d \tau_{c k}}-\mu \frac{d \hat{G}}{d \tau_{c k}}-\mu C_{k}\left(1-s_{G}\right) \theta
$$

where $\hat{G}$ is total government spending in real terms (adjusted for changes in the overall consumer price level), and $s_{G}$ is the share of government transfer payments in household income; and where

\footnotetext{
${ }^{8}$ In our model, all government revenue is returned in lump-sum fashion to households. The MCPF represents a different case, where the government spends the marginal revenue from a tax increase directly, without providing any additional lump-sum transfer to households.
} 


$$
\theta=\frac{\varepsilon_{C_{h} L}}{\sum_{i=1}^{M} s_{i} \varepsilon_{C_{i} L}}-1
$$

with $\varepsilon_{C_{i} L}$ denoting the compensated cross-price elasticity of demand for consumer good $i$ with respect to the price of leisure (the after-tax wage), and $s_{i}$ denoting the share of total income spent on good $I$.

The term $\theta$ expresses whether the taxed good is a stronger or weaker substitute for leisure than the average consumer good. When $\theta$ is positive (negative), the taxed good is a stronger (weaker) substitute than the average consumer good. An increase in the relative price of the taxed good will produce a smaller increase in leisure the smaller the value of $\theta$, that is, the weaker is the good's substitutability with leisure. When $\theta$ is negative, the tax on this good will exacerbate the labor market distortion by less than an increase in the labor tax (for an incremental increase in $\tau_{c k}$ from zero). This is consistent with the prior literature's result ${ }^{10}$ that the optimal commodity tax on a relative complement to leisure is higher than the optimal tax on other.

In the case where the taxed good is an average substitute (that is, where $\theta=0$ ), the effect of the tax can be expressed as (substituting (19) into (15) and rearranging):

$$
\frac{1}{\lambda} \frac{d U}{d \tau_{C k}}=\underbrace{\tau_{C k} \frac{d C_{k}}{d \tau_{C k}}}_{U E B}+\eta \sum_{i \neq k} \tau_{C i} \frac{d C_{i}}{d \tau_{C k}}+\eta \sum_{j=1}^{N} \tau_{I j} \frac{d I_{j}}{d \tau_{C k}}-\mu \frac{d \hat{G}}{d \tau_{C k}}
$$

Expression (21) reveals the marginal excess burden of a tax on an arbitrary consumer good in a world with pre-existing factor (labor) taxes. In (21) the tax-interaction effect consists of the last three terms plus $(\eta-1) \tau_{c k} \frac{d C_{k}}{d \tau_{c k}}$, which is part of the first term. The primary welfare effect is the other part of the first term, namely $\tau_{c k} \frac{d C_{k}}{d \tau_{c k}}$. We attach the label UEB to this term, to indicate that this is the (only) effect captured by the usual excess-burden formula.

\section{Excess Burden in the Absence of Other Commodity Taxes}

For simplicity, we start by examining the case where taxes on all goods except $C_{k}$ are equal to zero. In this case, equation (21) reduces to:

\footnotetext{
${ }^{9}$ For further discussion of the differences between the MEB and MCPF, see Ballard and Fullerton (1992) and Hakonsen (1998).

${ }^{10}$ See Corlett and Hague (1953), Harberger (1964), and Atkinson and Stiglitz (1972).
} 


$$
\frac{1}{\lambda} \frac{d U}{d \tau_{C k}}=\underbrace{\eta \tau_{c k} \frac{d C_{k}}{d \tau_{c k}}}_{U E B}-\mu \frac{d \hat{G}}{d \tau_{c k}}
$$

that is, the excess burden is the usual excess burden (UEB) times the MCPF from labor taxation, plus the marginal revenue from the consumer good tax times the MEB of the labor tax. Equation (22) indicates that the pre-existing labor tax magnifies the cost of the consumer good tax (first term) and also imposes an additional cost equal to the cost of raising the same amount of revenue through the labor tax (second term). Note that equation (22) collapses to the usual excess-burden formula when there is no prior tax on labor, in which case the MCPF equals one and the MEB falls to zero. Prior taxes are the source of the errors under the usual formula.

Expression (22) captures three distinct sources of excess burden. First, as in the first-best case, a tax on a consumer good distorts individuals' consumption decisions. This distortion creates a deadweight loss that follows the usual formula for the excess burden, equal to the wedge between the social cost of producing the taxed good and the price paid by the consumer, times the marginal change in consumption of the taxed good for a change in the tax rate. This gives the part of the first right-hand term in (22) labeled UEB.

Second, the consumer good tax exacerbates the pre-existing tax distortion in the labor market. The consumer good tax is implicitly a factor tax: by driving up the price of a consumer good, it lowers the real wage. For a good that is an average substitute for leisure, lowering the real wage in this fashion affects labor supply in the same way that an explicit tax on labor would. Part of the real-wage reduction is due to the government's need to increase the revenue obtained from distortionary taxes. The second right-hand term in (22) is the welfare cost that would result if the government had raised this additional revenue through an increase in the labor tax.

In fact, the revenue increase here is from the consumer-good tax. This gives rise to a third welfare effect, which is represented by another component of the first term in (22). Because it distorts consumption decisions (as well as labor-leisure choice), the tax on the consumer good is less efficient at raising revenue than a labor tax. This implies that the consumer good tax lowers the real wage by more than a labor tax that generates the same revenue. The further reduction in the real wage has a utility cost equivalent to the welfare cost from using a labor tax to raise an amount of revenue equal to the dollarequivalent of the first-best deadweight loss from the consumption distortion. This additional welfare cost is the second component of the first term in (22) - namely $(\eta-1) \tau_{c k} \frac{d C_{k}}{d \tau_{c k}}$. The first right-hand term in 
(22) represents the combination of this effect plus the direct loss from the consumption distortion described earlier. ${ }^{11}$

Equation (22) implies that as long as the taxed good is an average substitute for leisure (and other goods taxes are zero), raising revenue by taxing a consumer good is at least as costly as raising revenue through a labor tax. Even for a tax on a good with perfectly inelastic demand - which implies a zero excess burden under the usual formula - the cost of the tax is the same as raising the same amount of revenue using the labor tax. In this case, the first term in equation (22) goes to zero, just as in the usual formula, but the last term is still positive. This result may seem appear to contradict earlier optimal-tax results. In particular, Ramsey (1927) showed that if all goods demands are independent (i.e., if the crossprice elasticity between any two consumer goods is zero) then the optimal tax is inversely related to the elasticity of demand. A tax on a good with a perfectly inelastic demand, under these conditions, involves zero excess burden.

In fact there is no contradiction between this result and equation (22). The assumption that all cross-price elasticities are zero turns out to be very restrictive. As shown in Williams (1998b), when goods demands are independent, any good with a relatively inelastic demand must be more complementary to leisure than the average good. Hence the case of independent demands illustrates the general principle, noted above, that a tax on a good that is more (less) complementary to leisure than the average good will initially be less (more) costly than the labor tax. In the special case of perfectly inelastic demand for the taxed good, assuming independent goods demands implies that $\theta=-1$, and thus the tax-interaction effect from equation (19) equals zero, reproducing the Ramsey result. Typically, however, not all cross-price elasticities will be zero. In general there is no reason to expect that taxing a good with a zero own-price elasticity of demand involves zero excess burden, and in most cases it will be important to consider the other channels for excess burden captured in (22). Indeed, as suggested above and shown through the numerical simulations below, these other channels can be more important to the overall excess burden than the direct impacts considered by the usual excess-burden formula.

\section{Allowing for Prior Taxes on Other Commodities}

The discussion thus far has focused on the case where commodity taxes on all other goods are zero. The formula becomes somewhat more complicated if there are non-zero commodity taxes on other

\footnotetext{
${ }^{11}$ The first right-hand term in (21) depends on the MCPF because the deadweight loss in the market for good $k$ is a pure loss to consumers, implying that the effect on labor supply depends on the uncompensated elasticity. In contrast, the second right-hand term, which represents the loss from raising revenue, depends on the MEB because the additional revenue is returned to consumers. This implies that even if the uncompensated labor supply elasticity is zero, the excess burden of a tax will still exceed the usual formula, because the excess burden depends on both the MCPF (which goes to zero as the uncompensated elasticity goes to zero) and the MEB (which does not). If the additional revenue were instead spent on a public good, the second term would also depend on the MCPF.
} 
goods, as the second and third terms in equation (21) no longer necessarily equal zero. ${ }^{12}$ In this case, changing a consumer tax affects welfare not only through the effect of the tax on the market for the taxed good and on the distorted labor market, but also through its effect on the markets for other taxed goods.

The intuition behind this result is very similar to that for the effect in the distorted labor market. Since a commodity tax imposes a wedge between the private and social cost of a good, any decrease (increase) in consumption of that good will cause an additional drop (rise) in consumer welfare. The second and third terms in equation (21) describe the effect on the markets for other consumer goods and for intermediate inputs, respectively. Each of these terms is equal to the tax wedge for a given good, times the effect of the changing tax on demand for that good, times the MCPF, summed over all other consumer goods (for the second term in (21)) or all intermediate goods (for the third term). Thus, if a good is a complement to other taxed goods, it will be more costly to tax, whereas if it is a substitute for other taxed goods, it will be less costly to tax.

While the intuition behind these two terms may be fairly simple, it may be difficult to gauge the empirical values of these terms. One would need to know the cross-price elasticities between the good in question and all other goods subject to commodity taxation. However, as indicated earlier (see equation (16)), the importance of the tax-interaction in the market for a particular good should be roughly proportional to the tax revenue raised in that market. In the U.S., there are relatively few significant commodity taxes, except for broad consumption taxes (such as state sales taxes), whose impact can be captured in this model simply by renormalizing the labor tax. ${ }^{13}$ Thus, in the U.S. at least, the terms for interactions with other commodity taxes are likely to be relatively unimportant in comparison to the other terms in equation (21). Only in circumstances where there is a heavily taxed (or subsidized) consumer good that is a strong complement or substitute to the taxed good should these terms contribute importantly to excess burden.

\section{Effects of a Tax on an Intermediate Good}

Here we examine the effect of a tax on an intermediate good. Adopting an approach similar to that used in the previous section gives

$$
\frac{1}{\lambda} \frac{d U}{d \tau_{l k}}=\underbrace{\tau_{C k} \frac{d C_{k}}{d \tau_{l k}}}_{d W^{P}}+\underbrace{\sum_{i \neq k} \tau_{C i} \frac{d C_{i}}{d \tau_{l k}}+\sum_{j=1}^{N} \tau_{I j} \frac{d I_{j}}{d \tau_{l k}}-\tau_{L} \frac{d l}{d \tau_{I k}}}_{d W^{I}}
$$

\footnotetext{
${ }^{12}$ The second term, representing the effect of interactions with distorted markets for other consumer goods, will also be zero if consumer good demands are independent (zero cross-price elasticities).

${ }^{13}$ As is well known, in a static setting a labor tax is equivalent to a uniform set of consumer good taxes.
} 
As with the consumer good tax, the tax on an intermediate good affects welfare through its impacts on the market for the taxed good, the markets for other taxed goods, and the distorted labor market. The first term on the right-hand side represents the primary welfare effect (the effect on the market for the taxed good), while the remaining terms represent the tax-interaction effect (the effect on the markets for other taxed goods and on the distorted labor market).

Again following the same approach as in the previous section (see Appendix A for details), we arrive at the following expression for the tax-interaction effect:

$$
d W^{I}=(\eta-1) \tau_{I k} \frac{d I_{k}}{d \tau_{I k}}+\eta \sum_{i=1}^{M} \tau_{C i} \frac{d C_{i}}{d \tau_{I k}}+\eta \sum_{j \neq k} \tau_{l j} \frac{d I_{j}}{d \tau_{I k}}-\mu \frac{d \hat{G}}{d \tau_{I k}}-\mu_{I_{k}}\left(1-s_{G}\right) \theta
$$

where

$$
\theta=\frac{\sum_{i=1}^{M} \varepsilon_{c_{k} L} \alpha_{i k}}{\sum_{i=1}^{M} s_{i} \varepsilon_{C_{i} L}}-1
$$

and where $\alpha_{i j}$ is the fraction of the total production of intermediate good $j$ that is used in production of consumer good $i$.

The expression for $\theta$ is a bit different from the corresponding expression (20) associated with the tax on the consumer good. As with a tax on a consumer good, the welfare impact of the tax depends in part on how it affects the labor/leisure decision. However, because the intermediate good is not consumed by households, the impact on the labor/leisure decision is indirect. Now the labor supply effect of a tax on that good depends on the complementarity or substitutability with leisure of the consumer goods that are produced from the intermediate good. The right-hand side of (19') expresses these indirect complementarity and substitutability elements. If the average good produced from the taxed intermediate (weighted by the amount of the taxed intermediate used in each good) is more of a complement to leisure than the average consumer good (weighted by expenditure share), then $\theta$ will be negative, and the taxinteraction effect and excess burden from the tax will be relatively low.

For the average intermediate good, $\theta=0$ and the effect of the tax reduces to

$$
\frac{1}{\lambda} \frac{d U}{d \tau_{l k}}=\underbrace{\eta \tau_{l k} \frac{d I_{k}}{d \tau_{l k}}}_{U E B}+\eta \sum_{j \neq k} \tau_{l j} \frac{d I_{j}}{d \tau_{l k}}+\eta \sum_{i=1}^{M} \tau_{C i} \frac{d C_{i}}{d \tau_{l k}}-\mu \frac{d \hat{G}}{d \tau_{l k}}
$$

This expression has the same form as the corresponding expression for a consumer good tax (21). The first term is the usual excess-burden formula times the MCPF of the labor tax, and the second term is the MEB of the labor tax times the marginal revenue from the intermediate good tax.

Although (21') has a similar form to the analogous expression (21) for consumer good taxes, it does not imply intermediate input taxes have the same status as consumer good taxes in an optimal tax 
system. At the Diamond-Mirrlees optimum, the excess burden per marginal dollar of revenue from all taxes (on both intermediate inputs and consumer goods) is exactly the same. However, for intermediate inputs, the optimal tax rate at this optimum is exactly zero, whereas they need not be zero for consumer good taxes. Moreover, the equality of excess burdens at the optimum is consistent with the idea that strictly positive (or negative) taxes on intermediate inputs will have higher excess burdens than the excess burdens associated with the optimal values of consumer good (or intermediate good) taxes.

\section{An Implementable Formula}

The welfare-change formulas derived in the previous two sections apply only for marginal changes in the tax rate on a consumer or intermediate good. This section derives approximations for the effects of larger tax changes, and then rearranges these expressions to derive an implementable formula that expresses the excess burden in terms of observable quantities and estimable parameters.

Consider first a tax on the typical consumer good. Assuming that the marginal excess burden of labor taxation remains constant for a change in a commodity tax (a reasonable assumption so long as the change in the commodity tax is relatively small compared to the labor tax) and integrating over the change in the tax rate give

$$
\frac{1}{\lambda} \Delta U \approx \eta \underbrace{\int_{\tilde{\tau}_{c k}}^{\bar{\tau}_{C k} \frac{d C_{k}}{d \tau_{C k}} d \tau_{C k}}}_{U E B}+\eta \sum_{i \neq k} \tau_{C i} \Delta C_{i}+\eta \sum_{j=1}^{N} \tau_{l j} \Delta I_{j}-\mu \Delta \hat{G}
$$

For a tax on the typical intermediate good, the same procedure yields

$$
\frac{1}{\lambda} \Delta U \approx \eta \underbrace{\int_{0}^{\bar{\tau}_{1 k}} \tau_{l k} \frac{d I_{k}}{d \tau_{l k}} d \tau_{l k}}_{U E B}+\eta \sum_{i=1}^{M} \tau_{c i} \Delta C_{i}+\eta \sum_{j \neq k} \tau_{l j} \Delta I_{j}-\mu \Delta \hat{G}
$$

These formulas are very similar to the marginal formulas in the previous two sections. Each term has the same interpretation as before.

The usual excess-burden formula for a non-marginal change often assumes a linear demand curve, giving a first-order approximation for the welfare effect of the tax - the familiar Harberger triangle. The same linearity assumption can be applied here to produce a first-order approximation for the welfare effect including second-best effects, yielding

$$
\frac{1}{\lambda} \Delta U \approx \underbrace{\frac{1}{2} \tau_{c k} \Delta C_{k}}_{U E B}+\eta \sum_{i \neq k} \tau_{c i} \Delta C_{i}+\eta \sum_{j=1}^{N} \tau_{l j} \Delta I_{j}-\mu \Delta \hat{G}
$$

for a tax on a consumer good and 


$$
\frac{1}{\lambda} \Delta U \approx \underbrace{\frac{1}{2} \tau_{l k} \Delta I_{k}}_{U E B}+\eta \sum_{i=1}^{M} \tau_{C_{i}} \Delta C_{i}+\eta \sum_{j \neq k} \tau_{l j} \Delta I_{j}-\mu \Delta \hat{G}
$$

for a tax on an intermediate good.

Equations (24) and (24') are much the same as (23) and (23'), and the interpretation of each term is the same. Each of these two equations simply replaces each of the terms from equation (23) or (23') with a first-order approximation of that term, thus yielding a closed-form formula for the total cost of a tax. For a non-linear demand curve, these approximations will introduce some error. However, they will be roughly as accurate for the second-best case as the usual formula is for the first-best case. Moreover, as indicated below, in a second-best setting they will be vastly more accurate than the usual formula is in that setting. ${ }^{14}$

While the formulas derived so far provide clear intuition, they may prove difficult to use in practice, because they require knowledge of parameters that may be difficult to estimate. In particular, calculating the net change in real government revenue requires knowledge not only of the additional revenue from the consumer or intermediate good tax in question, but also of the change in labor tax revenue and the change in the overall price level that result. However, (24) and (24') can be rewritten as functions of the revenue directly raised by the new tax, rather than of the net change in real government revenue. Ignoring taxes on other goods, ${ }^{15}$ (24) can be expressed (see Appendix A for derivation) as:

$$
\frac{1}{\lambda} \Delta U \approx \alpha \frac{1}{2} \tau_{C k} \Delta C_{k}-\beta \tau_{C k} C_{k}
$$

where $\alpha=\eta-\frac{\mu}{1+\mu}\left(\eta-1+s_{G}\right)$ and $\beta=\mu-\frac{\mu}{1+\mu}\left(\mu+s_{G}\right)$.

As in expression (24), the first term is a multiple of the usual excess-burden formula, and the last term is a function of the revenue raised, with the middle two terms dropped because expression (25) ignores taxes on other goods. Equation (24) referred to the net revenues from the new commodity tax; that is, the revenues earned net of the (negative) revenue impact associated with changes in labor supply. In contrast, equation (25) refers to the gross revenues from the new tax, which makes the formula much easier to

\footnotetext{
${ }^{14}$ These two formulas can be simplified further by ignoring taxes on other goods, which will cause the second and third terms to drop out. As indicated by sections IIB and IIC, if the revenues from these other taxes represent a small share of overall revenues, the error implied by ignoring the second and third terms will be small.

${ }^{15}$ If other taxes were not ignored, expression (25) would take the form $\frac{1}{\lambda} \Delta U \approx \alpha \frac{1}{2} \tau_{C k} \Delta C_{k}+(\alpha-\beta)\left(\sum_{i \neq k} \tau_{C i} \Delta C_{i}+\sum_{j=1}^{M} \tau_{l j} \Delta I_{j}\right)-\beta \tau_{C k} C_{k}$, and expression (25') would change in the same manner.
} 
implement. In (25) the coefficients $\alpha$ and $\beta$ differ slightly from $\eta$ and $\mu$, because the difference between the gross and net change in government revenue is incorporated into these terms.

The analogous expression for a tax on an intermediate good is:

$$
\frac{1}{\lambda} \Delta U \approx \alpha \frac{1}{2} \tau_{I k} \Delta I_{k}-\beta \tau_{I k} I_{k}
$$

The information required to calculate the value of expression (25) or (25') is that required to calculate the usual excess-burden formula, plus the values of the parameters $\alpha$ and $\beta$. These parameters depend only on the marginal excess burden and marginal cost of public funds of the labor tax, and on the share of government spending in household income. The marginal excess burden and marginal cost of public funds, in turn, can be expressed in terms of the compensated and uncompensated elasticities of labor supply and the labor tax rate. ${ }^{16}$ Note that the parameters $\alpha$ and $\beta$ will be the same regardless of the particular commodity that is taxed.

\section{How Accurate Are the Excess-Burden Approximations under the Usual and New Formulas?}

\section{A. The Numerical Model}

The foregoing theoretical considerations indicate the conceptual superiority of the new formulas for excess burden, but they do not fully convey the quantitative significance of the conceptual advantage. To gauge the accuracy of the new formulas relative to the usual formula, we employ a simple numerically-solved general equilibrium model. We solve this model to determine "true" excess burden for a given tax, where the excess burden is measured using the equivalent variation. ${ }^{17}$ We then compare this "true" burden with the approximations to excess burden under the usual formula and the new formulas.

The numerical model has the same formal structure as that of the analytical model but specifies a particular set of goods and particular functional forms. The model distinguishes four intermediate good industries (energy, services, agriculture, and manufactures) and five consumer good industries (consumer services, consumer manufactures, transportation, utilities, and food \& tobacco), the last of which is further disaggregated (giving six consumer good industries) to analyze the cigarette tax. Just as in the

${ }^{16}$ Specifically, $\mu=\frac{\tau_{L} \varepsilon_{L}^{C}}{\left(1-\tau_{L}\right)-\tau_{L} \varepsilon_{L}}$ and $\eta=\frac{\left(1-\tau_{L}\right)}{\left(1-\tau_{L}\right)-\tau_{L} \varepsilon_{L}}$, where $\varepsilon_{L}^{C}$ and $\varepsilon_{L}$ are the compensated and uncompensated elasticities of labor supply.

${ }^{17}$ We also compute the compensating variation. In every case we consider, the difference between the equivalent variation and compensating variation is less than two percent of either measure. 
analytical model, households supply labor to firms and receive income in the form of wages and government transfers, which are funded through commodity taxes and a labor tax. Consumption and leisure are assumed to be separable in the household utility function, implying that all consumer goods are equal substitutes for leisure. The utility function and all production functions follow a constant-elasticityof-substitution (CES) form. ${ }^{18}$

The model is calibrated to match the United States economy in 1995, using data from the Survey of Current Business. We assume an uncompensated labor supply elasticity of 0.15 , a compensated elasticity of 0.40 , and a labor tax rate of forty percent, which together imply that the partial-equilibrium MCPF is 1.11 and the partial-equilibrium MEB is $0.296 .^{19}$

We consider the welfare impacts from the imposition of two new taxes: a cigarette tax and a tax on energy use. ${ }^{20}$ For each tax, we consider a range of tax rates and elasticities. For the cigarette tax, we use three different estimates for the own-price demand elasticity for cigarette consumption $-0.2,0.4$, and 0.8 - which span a range somewhat broader than most estimates. ${ }^{21}$ We consider a low-case tax rate of $14.1 \%$ ( $\$ 0.265$ per pack), which is equal to the current federal rate plus the lowest state excise tax; a central-case tax rate of $31.3 \%$ ( $\$ 0.59$ per pack), equal to the federal rate plus the average state tax; and a high case rate of $65.3 \%$ ( $\$ 1.23$ per pack), equal to the federal rate plus the average state rate, plus the additional charges in the proposed tobacco settlement, which amount to roughly $\$ 0.64$ per pack of cigarettes sold.

For the energy tax, we use elasticities of $0.6,0.9$, and 1.35 , which again is a somewhat broader range than most estimates. ${ }^{22}$ We take 5 percent as a central case for the tax rate (which is roughly

\footnotetext{
${ }^{18}$ This model is similar to the numerical model used by Parry, Williams, and Goulder (1999) to examine the cost of environmental regulation in the presence of pre-existing tax distortions, but differs in that it involves different industry classifications does not consider environmental externalities. Details of the model used here appear in Appendix B.

${ }^{19}$ These labor supply elasticities represent central estimates from the literature (see Russek (1996) for a survey). A tax rate of 40 percent is similar to that used in other studies (see Browning (1987) and Lucas (1990) for example). The resulting MCPF and MEB estimates are broadly consistent with studies of the cost of taxation (see Ballard et al. (1985) or Browning (1987)).

${ }^{20}$ While both goods involve substantial negative externalities, we ignore such externalities here. The purpose of this exercise is to illustrate the importance of considering pre-existing taxes in estimating the (gross) excess burden, not to consider the benefits provided by these policies.

${ }^{21}$ Estimates of the demand elasticity for cigarettes range from 0.25 to 0.7 , centering around a value of 0.4 . See Congressional Budget Office (1998) for a survey of cigarette demand elasticity estimates.

${ }^{22}$ Most estimates of the demand elasticity for energy use are slightly below 1 . See, for example, Jorgenson and Wilcoxen (1990).
} 
equivalent to the BTU tax proposed by President Clinton in 1993) and also consider tax rates that are one half and twice that rate. In evaluating each tax, we assume that no other commodity taxes are present.

\section{B. Results}

Table 1 indicates the differences in the accuracy of the alternative formulas. For each case, the table shows the "true" excess burden as calculated by the numerical model and the approximated excess burden under both the usual formula and the new formula introduced in this paper. (In applying the new formula, we use equation (25) and (25') for the cigarette tax and energy tax, respectively.) The table also shows the percentage errors under each approximation. ${ }^{23}$

This table demonstrates that the usual formula is substantially inaccurate in the presence of a preexisting labor tax. In all but one case, it yields an approximation that is less than half the true excess burden of a given tax, and in several cases it yields a value which is less than one-tenth the true cost! This indicates that the downward bias of the simple formula can be dramatic, and that previous studies of the cost of commodity taxes that have used this simple formula may have seriously underestimated the cost of such taxes.

This error arises because the usual formula only considers one component of the excess burden namely, the deadweight loss in the market for the taxed good - and ignores interactions with other markets. Numerical results indicate that very little of the error comes from the linear approximation. In none of the cases in the table is the error from taking a linear approximation much more than ten percent, and in most cases it is less than five percent. ${ }^{24}$ Indeed, for the usual formula, the linear approximation may help reduce the error in the excess-burden estimate. If supply is linear (e.g., perfectly elastic) and demand curves are convex (as is typically the case), the linear approximation yields a higher estimate than would a method that estimates the excess burden region through integration. Hence the error associated with the linear approximation can partly offset the error from omitting interactions with other markets.

The usual excess-burden formula is most accurate for high tax rates levied against goods with relatively elastic demand. In these cases, the distortion in the market for the taxed good (which is captured by the usual formula) is relatively large compared to the additional distortion in the labor market (which is ignored by the usual formula), and thus the usual formula captures a relatively large portion of the total excess burden. When the tax rate is low or demand is inelastic, the usual formula is off by much more. In contrast, the new formula introduced in this paper provides a very close approximation to the

\footnotetext{
${ }^{23}$ In calculating the approximation for excess burden under both the old and new formulas, we use the actual change in consumption of the taxed good, as taken from the numerical model, rather than simply plug in the relevant elasticity to infer a change in consumption.

${ }^{24}$ We establish this by calculating the integral of the usual formula for marginal excess burden for each policy, and comparing this to the value obtained using a linear approximation.
} 
true excess burden. The largest error under this formula is eleven percent, and in most cases the formula is off by less than three percent. In practice, errors of such small magnitude will be insignificant relative to uncertainty in estimating the elasticity parameters involved in the calculation.

Figure 2 provides further comparisons of the errors under the different formulas, for the energy tax and cigarette tax, respectively. This figure displays the "true" excess burden and the approximated excess burden from the usual and new formulas, over a range of values for the energy and cigarette tax rates. The various panels in the figure show the results under three different pre-existing labor tax rates: 20,40 and 60 percent. $^{25}$

This figure demonstrates two important points. First, while the excess burden as measured by the usual formula is roughly proportional to the square of the (consumer or intermediate good) tax rate, the "true" excess burden and the new formula are roughly linear with respect to the tax rate, at least over a reasonable range. This reflects the fact that, over the range of tax changes considered, the newly introduced (cigarette or energy) tax remains a fairly small component of the overall effective tax on labor (the labor tax itself is the more important component). The bulk of the excess burden from the new tax comes from the interaction with the labor market, not the deadweight loss in the market for the taxed good itself! Hence the level of the new tax intermediate or final good tax has relatively little effect on the marginal distortion in the labor market, and the overall excess burden is close to linear with respect to the rate of the new tax.

Second, the relative accuracy of the usual formula as compared with the new formula varies with

the pre-existing labor tax rate. As the pre-existing labor tax rate rises, interactions with the tax-distorted labor market become more important, and the error in the usual formula is greater. With a pre-existing labor tax rate of zero, the welfare effect of interactions with the labor market disappears, and the usual formula and the new formula give identical answers. Figure 2 shows that, even for a relatively low preexisting labor tax rate of twenty percent, the new formula is still far more accurate than the usual formula in measuring excess burden.

\section{Extensions}

This section extends the analytical model of Section II in two ways. First, it generalizes the production function for intermediate goods to include other intermediate goods as inputs, as well as labor. Second, it examines how the results will differ if production is not perfectly competitive in the taxed industry. 


\section{A. Generalized Production Function for Intermediate Goods}

Here we allow intermediate goods to be produced with both intermediate goods and labor, rather than only from labor as in the previous model. Thus, the intermediate good production function follows

$$
I_{i}=F_{I i}\left(L_{l i}, I_{I i 1} \ldots I_{l i N}\right)
$$

where $I_{i i j}$ is the amount of intermediate good $j$ used in production of intermediate good $i$. The supply and demand for intermediate goods then follow

$$
I_{j}=\sum_{i=1}^{M} I_{i j}+\sum_{i=1}^{N} I_{I j}
$$

and the first-order conditions for firm profit-maximization give the price of intermediate good $i$ as

$$
p_{I i}=\tau_{l i}+\frac{1}{\partial F_{l i} / \partial L_{l i}}=\tau_{I i}+\frac{p_{l j}}{\partial F_{l i} / \partial I_{l i j}}
$$

Following the same set of steps as in Section II.C, but using equations (26), (27) and (28) in place of the corresponding equations (3), (4), and (9) gives the same result as equation (19'), but the expression for $\theta$ now differs from equation (20')

$$
\theta=\frac{\sum_{i=1}^{M} \eta_{c_{k} L} \sum_{j=1}^{N} I_{i j} \Gamma_{j} I_{k}^{-1}}{\sum_{i=1}^{M} s_{i} \varepsilon_{c_{i} L}}-1
$$

where $\Gamma$ is the vector of total derivatives of the intermediate good prices with respect to the tax $\tau_{I k}$. $\Gamma$ is given by

$$
\Gamma=X^{-1} \Phi
$$

where $\Phi$ is the vector of derivatives of intermediate good tax rates with respect to $\tau_{I k}$ (where all but the $k$ th element equal zero, and the $k$ th element equals 1 ) and $X$ is the matrix of intermediate input intensities, given by

$X_{i j}=O_{i j}-\frac{I_{i j}}{I_{i}}$

where $O_{i j}$ equals 1 when $i=j$ and equals zero otherwise.

This expression is more complicated than the analogous expression from the simpler model. As before, the numerator in (29) is a weighted average of the cross-elasticities with leisure for the consumer goods produced using a given intermediate good. Here, though, an intermediate good tax affects not only consumer good prices, but also the prices of other intermediate goods, so that the determination of the impact on consumer good prices is more complicated. Still, it can be shown that

\footnotetext{
${ }^{25}$ For given utility function parameters, the elasticities of demand for the different consumer goods and the labor supply elasticities will change as the pre-existing labor tax varies. We recalibrate the utility function for each level of the pre-existing labor tax in order to hold these elasticities constant across scenarios.
} 


$$
\sum_{i=1}^{M} \sum_{j=1}^{N} I_{i j} \Gamma_{j} I_{k}^{-1}=1
$$

or, in other words, that the weights in the numerator of (29) sum to 1. This implies that, just as in the simpler previous model, $\theta=0$ for a tax on the average intermediate good (or on any intermediate good if leisure and consumption are weakly separable). Thus, since equation (20') is unchanged, and $\theta=0$ for the average good, equation (21') applies even in this extended model. The more general production specification for intermediate goods does not alter the results in any fundamental way.

\section{B. Imperfect Competition}

The model presented in Section II assumed competitive production, implying that output is priced at marginal cost. In any industry that is not perfectly competitive, output prices can be expected to exceed marginal cost. The distortion resulting from imperfect competition will alter the excess burden of any tax that affects demand in that market. ${ }^{26}$ This section allows for industry output to be priced above marginal cost, and examines how this alters the results from Section II. For compactness, we only derive a formula for the case of a tax on a consumer good, but the formula for an intermediate good tax would parallel this result in the same manner that equation (21) parallels equation (21').

We model imperfect competition implicitly, assuming that prices in each industry are marked up by the amount $m_{C i}$ or $m_{I j}$ for consumer or intermediate goods, respectively. For our purposes, the specifics of imperfect competition are not important - only the effect on price matters. Representing imperfect competition in this way allows us to obtain a result applicable to a wide range of market structures. ${ }^{27}$ Consumer good prices are given by

$$
p_{C i}=\tau_{C i}+m_{C i}+\frac{1}{\partial F_{i} / \partial L_{C i}}=\tau_{C i}+m_{C i}+\frac{p_{i j}}{\partial F_{i} / \partial I_{i j}}
$$

and intermediate good prices are given by

$$
p_{I j}=\tau_{I j}+m_{l j}+1
$$

Under imperfect competition, $m$ will tend to be positive. The magnitude of $m$ will depend on a number of factors, including the nature of imperfect competition in the industry, the elasticity of demand, and (as shown by Bishop (1968)) whether the good is subject to a specific or an ad valorem tax. For example, under a Cournot oligopoly (and no ad valorem tax) $m$ would follow

\footnotetext{
${ }^{26}$ Browning (1997) also analyzes the interactions between imperfect competition and taxes, though for a different purpose. The analysis in this section addresses how imperfect competition alters the cost of taxes, while Browning's analysis addresses how prior taxes alter the cost of imperfect competition.

${ }^{27}$ However, since our model does assume constant returns in production, it suggests that imperfect competition is due to an entry barrier rather than a situation of natural monopoly.
} 


$$
m_{C i}=-\frac{C_{i}}{J_{C i} \frac{\partial C_{i}}{\partial p_{C i}}}
$$

where $J_{C i}$ is the number of firms producing good $C_{i}$. Note that $m$ is not fixed; it can (and, under most forms of imperfect competition, will) vary in response to changes in tax rates.

Since production is assumed to possess constant returns to scale, any industry that prices output above marginal cost will realize profits. These profits are assumed to flow to consumers, who own firms. Thus, the consumer budget constraint now follows

$$
\left(1-\tau_{L}\right)_{L}+G+\pi=\sum_{i=1}^{M} p_{C i} C_{i}
$$

where $\pi$ represents total profits across all industries, given by

$$
\pi=\sum_{i=1}^{M} m_{C i} C_{i}+\sum_{j=1}^{N} m_{l j} I_{j}
$$

Following the same approach used in Section II, using equations (35), (32), and (33) in place of the corresponding equations (7), (8), and (9), and assuming that all consumer goods are equal substitutes for leisure (or, equivalently, that leisure is weakly separable in the utility function) give

$$
\frac{1}{\lambda} \frac{d U}{d \tau_{C k}}=\underbrace{\eta \tau_{C k} \frac{d C_{k}}{d \tau_{c k}}}_{U E B}+\eta m_{C k} \frac{d C_{k}}{d \tau_{C k}}+\eta \sum_{i \neq k}\left(\tau_{C i}+m_{C i}\right) \frac{d C_{i}}{d \tau_{C k}}+\eta \sum_{j=1}^{N}\left(\tau_{l j}+m_{l j}\right) \frac{d I_{j}}{d \tau_{C k}}-\mu \frac{d \hat{G}}{d \tau_{C k}}-\mu \frac{d \hat{\pi}}{d \tau_{C k}}
$$

This result is similar in concept to the analogous equation under perfect competition, equation (21). The first three terms are the cost of distorting consumption, magnified by the interaction with the distorted labor market. These terms equal the sum over all goods of the difference between the social cost and private cost for a given good. This difference now equals the price markup from imperfect competition plus the tax on that good times the change in demand for that good, multiplied by the MCPF of the labor tax. As under perfect competition, there is a cost to raising revenue, equal to the cost of raising the equivalent revenue with a labor tax. Thus, this term equals the MEB of the labor tax times the marginal revenue. Finally, there is an additional term representing the cost of firm profits from imperfect competition. This term takes a similar form to the term for cost of commodity tax revenue just discussed, equal to the MEB of the labor tax times profits. The terms are similar because the effects of taxation and of price markups are the same for the average individual: both cause prices to exceed the social marginal cost of production, and both transfer the resulting revenue (either in the form of government transfers or profits to firm owners) back to consumers.

Equation (37) shows that it generally will be more expensive to tax a good that is produced under imperfect competition than one produced under pure competition. This squares with what a partialequilibrium analysis would indicate. Unless the markup from imperfect competition declines 
substantially as the tax rate increases $\left(d m_{C k} / d \tau_{C k}<0\right)$ the marginal cost of a tax will be higher if the taxed good is produced under imperfect competition. The reason is clear: imperfect competition causes the private cost of a good to exceed the social cost. Taxing that good reduces demand, which exacerbates the distortion from imperfect competition. The presence of other taxes (on goods or labor) complicates the result, but in this case, the partial-equilibrium result that taxes are more expensive when levied on a good produced under imperfect competition tends to carry through to the general-equilibrium analysis.

\section{Conclusions}

The formula typically used to approximate excess burden performs poorly when applied to commodity (intermediate-input and consumer-good) taxes. Its poor performance reflects the fact that it does not consider how commodity taxes interact with pre-existing distortionary taxes, augmenting the distortions in other markets occasioned by prior taxes in these markets.

Although previous theoretical work indicates the relevance of such interactions to overall excess burden, it offers no clues as to which interactions are most important. It leaves open the possibility that such interactions will only slightly influence the excess burden of a new commodity tax, and even allows for the possibility that they will reduce the overall excess burden. Moreover, prior work does not offer a practical alternative to the simple excess-burden formula. Faced with uncertainties as to the significance of interactions with other markets, and with the absence of a practical alternative, economists continue to disregard these interactions and to adopt the usual excess-burden formula in applied work.

This paper helps fill the gap between theory and practice. It shows that the relative importance of the interaction with a given pre-existing tax is roughly proportional to the revenue raised by that tax. This suggests that the distortions from factor taxes are the most important to consider, because in most industrialized countries, the majority of government revenue is generated by factor taxes. In addition, the paper provides an alternative to the simple excess-burden-triangle formula, by deriving an empirically implementable formula for evaluating the excess burden from a commodity tax.

Finally, the paper illustrates the quantitative significance of accounting for prior factor-market distortions in the evaluation of excess burden. For realistic central parameter values and for a wide range of assumed rates for prior taxes, the usual excess-burden formula substantially understates the excess burden of taxes on commodities, capturing less than half of the excess burden. Even when low values (20 percent) are used for prior tax rates on labor, the usual formula captures no more than 65 percent of the excess burden. When the newly introduced tax is "small," the usual formula can be spectacularly wrong, 
giving a result less than five percent of the true excess burden. In contrast, for the same parameters and range of tax rates, our alternative formula yields estimates that are within five percent of the actual excess burden.

These results reveal the critical significance of factor-market distortions to assessments of excess burden of commodity taxes. Indeed, the additional distortions generated in factor markets are responsible for most of the excess burden from the taxes on intermediate inputs and commodities. The "direct" excess burden from the distortion generated in the market for the taxed intermediate or consumer good is less important. What we might ordinarily consider to be the first-order distortionary impact of a commodity tax - the distortion in the newly taxed market - turns out to be second-order!

These results have significant implications for future empirical work on the excess burden of particular commodity taxes. Studies using the usual excess-burden approximation will substantially understate the true cost of commodity taxes, in some cases quite dramatically. While our alternative approximation is slightly more complex, it is not much more difficult to implement than the usual formula.

Our results also have implications for tax policy. First, they reinforce the notion that broad-based factor taxes tend to be more efficient means of raising revenue than taxes on particular commodities. In addition, to the extent that input and commodity taxes have higher distortionary costs than previously recognized, efficiency will require higher benefits from the projects that these taxes help finance: that is, the minimal benefits necessary to pass a benefit-cost test will be higher.

Some limitations of the present study deserve mention. First, the general-equilibrium framework considers only one primary factor of production (labor). Since commodity taxes are implicit factor taxes, in assessing excess burden one ideally would want to account for how a commodity tax might augment or reduce inefficiencies in the relative taxation of different factors such as capital and labor. ${ }^{28}$ This would require a model with multiple factors. Although considering multiple factors would refine the analysis, we would not expect it to alter the qualitative findings obtained here.

Second, while our analytical model allows all goods to be complements or substitutes with leisure, our alternative approximation formula relies on the assumption that the taxed good is an average substitute for leisure. As discussed above, the excess burden would differ if the taxed commodity were an exceptionally strong or weak substitute with leisure. Since the actual degree of complementarity or substitutability with leisure is uncertain, any formula for excess burden must ultimately yield estimates that involve uncertainty. However, this does not alter the fact that, for the typical good, our alternative formula will be more accurate (and often far more accurate) than the usual formula. As this paper shows,

${ }^{28}$ Bovenberg and de Mooij (1998) analyze these issues in the context of assessing the costs of revenue-neutral environmental tax reforms. 
our formula is on the mark for the case where the taxed good is typical (an average substitute for leisure), while the usual formula performs poorly in this central case. ${ }^{29}$

Finally, although our approximation formula includes a term accounting for prior taxes on other commodities, it is difficult to estimate the cross-price elasticities necessary to calculate that term, and so it may be necessary in practice to omit it. However, in the U.S., where commodity taxes play a relatively minor role, ignoring such taxes may not have much quantitative importance. We would emphasize the importance of accounting for prior factor taxes, which contribute fundamentally to overall tax revenues and which, as mentioned above, contribute much more to excess burden than the "direct" distortions considered by the usual approximation formula.

\footnotetext{
${ }^{29}$ The usual formula would provide a good approximation to excess burden if there were no other taxes on commodities and the newly taxed good were strongly complementary with leisure. It could also give a good approximation if there were another taxed commodity (i.e., consumer good) that represented a strong substitute for the newly taxed commodity. But one could just as easily reverse these examples, giving a situation in which the usual formula is even further off the mark than in the central case we consider.
} 


\section{References}

Atkinson, A.B. and J.E. Stiglitz, 1972. "The Structure of Indirect Taxation and Economic Efficiency." Journal of Public Economics 1:97-119.

Auerbach, Alan J., 1985. "The Theory of Excess Burden and Optimal Taxation." In A. J. Auerbach and M. Feldstein, eds., Handbook of Public Economics, vol. I. Amsterdam: North-Holland.

Ballard, Charles L., and Don Fullerton, 1992. "Distortionary Taxes and the Provision of Public Goods." Journal of Economic Perspectives 6(3), 117-131.

Ballard, Charles L., John B. Shoven, and John Whalley, 1985. "General Equilibrium Computations of the Marginal Welfare Costs of Taxes in the United States." American Economic Review 77, 11-23.

Bishop, R. L., 1968. "The Effects of Specific and Ad Valorem Taxes." Quarterly Journal of Economics $82: 198-218$.

Boadway, R. and R. Harris, 1977. "A Characterization of Piecemeal Second Best Policy” Journal of Public Economics 8:169-90.

Bovenberg, A. Lans, and Ruud A. de Mooij, 1994. "Environmental Levies and Distortionary Taxation." American Economic Review 84(4):1085-9.

Bovenberg, A. Lans, and Ruud A. de Mooij, 1998. "Environmental Taxes, International Capital Mobility, and Inefficient Tax Systems: Tax Burden vs. Tax Shifting." International Tax and Public Finance 5(1):7-40.

Bovenberg, A. Lans, and F. van der Ploeg, 1994. "Environmental Policy, Public Finance and the Labour Market in a Second-Best World," Journal of Public Economics 55:349-70.

Browning, Edgar K., 1987. “On the Marginal Welfare Cost of Taxation.” American Economic Review 77: 11-23.

Browning, Edgar K., 1997. "The Welfare Cost of Monopoly and other Output Distortions." Journal of Public Economics 66: 127-144.

Congressional Budget Office, 1998. The Proposed Tobacco Settlement: Issues From a Federal Perspective

Corlett, W. J., and D. C. Hague, 1953. "Complementarity and the Excess Burden of Taxation” Review of Economic Studies 21:21-30.

Diamond, P. A. and J. A. Mirrlees, 1971. "Optimal Taxation and Public Production I-II.” American Economic Review, 61:8-27, 61:261-278

Dixit, A. K., 1975. "Welfare Effects of Tax and Price Changes" Journal of Public Economics 4:103-123

Goulder, Lawrence H., 1995a. "Environmental Taxation and the 'Double Dividend:' A Reader's Guide," International Tax and Public Finance 2(2):157-83. 
Goulder, Lawrence H., 1995b. "Effects of Carbon Taxes in an Economy with Prior Tax Distortions," Journal of Environmental Economics and Management.

Goulder, L. H., I. W. H. Parry, and D. Burtraw, 1997. "Revenue-Raising vs. Other Approaches to Environmental Protection: The Critical Significance of Pre-Existing Tax Distortions." Rand Journal of Economics 28:708-731.

Hakonsen, Lars, 1998. “An Investigation into Alternative Representations of the Marginal Cost of Public Funds, International Tax and Public Finance 5:329-43.

Harberger, A. C., 1964a. "Taxation, Resource Allocation, and Welfare" in The Role of Direct and Indirect Taxes in the Federal Revenue System, Princeton University Press

Harberger, A. C., 1964b. "The Measurement of Waste” American Economic Review Papers and Proceedings 54:58-76

Hines, James R., Jr., 1999. “Three Sides of Harberger Triangles.” Journal of Economic Perspectives, forthcoming.

Jorgenson, Dale W. and Peter J. Wilcoxen, 1990. "Environmental Regulation and U.S. Economic Growth, The Rand Journal of Economics 21(2):314-40.

Lucas, Robert E., 1990. "Supply-Side Economics: An Analytical Review." Oxford Economic Papers 42:293-316.

Parry, I. W. H., 1995. "Pollution Taxes and Revenue Recycling." Journal of Environmental Economics and Management, 29:S64-S77

Parry, I. W. H., 1997. "Environmental Taxes and Quotas in the Presence of Distorting Taxes in Factor Markets," Resource and Energy Economics 19:203-20.

Parry, I. W. H., R. C. Williams III, and L. H. Goulder, 1999. "When Can Carbon Abatement Policies Increase Welfare? The Fundamental Role of Distorted Factor Markets." Journal of Environmental Economics and Management, 37:52-84.

Ramsey, F. P., 1927. “A Contribution to the Theory of Taxation.” Economic Journal 37:47-61

Russek, F., 1996. “Taxes and Labor Supply.” working paper, Congressional Budget Office.

Williams, R. C., 1998a. "Revisiting the Cost of Protectionism: The Role of Tax Distortions in the Labor Market." Journal of International Economics, forthcoming.

Williams, R. C., 1998b. “Optimal Taxes, Tax Interactions, and the Structure of Preferences.” working paper, Stanford University 


\section{Appendix A: Analytical Model Derivations}

Derivation of Equations (19) and (20)

The expression for the tax-interaction effect from equation (15) is:

$$
d W^{I}=\sum_{i \neq k} \tau_{C i} \frac{d C_{i}}{d \tau_{c k}}+\sum_{j=1}^{N} \tau_{l j} \frac{d I_{j}}{d \tau_{c k}}-\tau_{L} \frac{\partial l}{\partial \tau_{c k}}
$$

The consumer good tax affects labor supply by increasing the price of consumer good $k$ and by changing the level of transfer income households receive. (A1) is thus equivalent to:

$$
d W^{I}=\sum_{i \neq k} \tau_{C i} \frac{d C_{i}}{d \tau_{C k}}+\sum_{j=1}^{N} \tau_{l j} \frac{d I_{j}}{d \tau_{C k}}-\tau_{L} \frac{\partial l}{\partial p_{C_{k}}}-\tau_{L} \frac{\partial l}{\partial Y}\left\lfloor C_{k}+\sum_{i=1}^{M} \tau_{C i} \frac{\partial C_{i}}{\partial \tau_{C k}}+\sum_{j=1}^{N} \tau_{l j} \frac{\partial I_{j}}{\partial \tau_{C k}}-\tau_{L} \frac{\partial l}{\partial \tau_{C k}}\right\rfloor
$$

where $Y$ is total household income, given by $Y=\left(1-\tau_{L}\right) L+G$

The Slutsky equation gives

(A3) $\frac{\partial l}{\partial p_{C i}}=\frac{\partial l^{c}}{\partial p_{C_{i}}}-\frac{\partial l}{\partial Y} C_{i}$

and

(A4) $\frac{\partial l}{\partial \tau_{L}}=\frac{\partial l^{c}}{\partial \tau_{L}}-\frac{\partial l}{\partial Y} L$

Taking a derivative of the household utility function (1) while holding utility constant, and substituting in the consumer first-order conditions (10) yield

$$
\frac{\partial l^{C}}{\partial \tau_{L}}=-\frac{\partial l^{C}}{\partial\left(1-\tau_{L}\right)}=\sum_{i=1}^{M} \frac{p_{C i}}{1-\tau_{L}} \frac{\partial C_{i}^{C}}{\partial\left(1-\tau_{L}\right)}
$$

Finally, the Slutsky symmetry property gives

(A6) $\frac{\partial l^{C}}{\partial p_{C_{i}}}=\frac{\partial C_{i}^{C}}{\partial\left(1-\tau_{L}\right)}$

Rearranging (A2) and substituting in equations (A3) through (A6) yield

$$
d W^{I}=(\eta-1) \tau_{c k} \frac{d C_{k}}{d \tau_{C k}}+\eta \sum_{i \neq k} \tau_{C i} \frac{d C_{i}}{d \tau_{C k}}+\eta \sum_{j=1}^{N} \tau_{l j} \frac{d I_{j}}{d \tau_{C k}}-\mu\left(\frac{d G}{d \tau_{C k}}-\frac{G s_{k}}{p_{C k}}\right)-\mu\left(1-s_{G}\right) C_{k}\left(\frac{\varepsilon_{C_{k} L}}{\sum_{i=1}^{M} s_{i} \varepsilon_{C_{i} L}}-1\right)
$$

where $\varepsilon_{C_{i} L}=\frac{\partial C_{i}^{C}}{\partial\left(1-\tau_{L}\right)} \frac{\left(1-\tau_{L}\right)}{C_{i}} s_{i}=\frac{p_{C_{i}} C_{i}}{\sum_{j=1}^{M} p_{C_{j}} C_{j}}$ and $s_{G}=\frac{G}{\left(1-\tau_{L}\right) L+G}$

Derivation of Equations (19') and (20') 
The derivation of equations (19') and (20') for a tax on an intermediate good is similar to the derivation of equations (19) and (20) for a tax on a consumer good. In this case, the expression for the tax-interaction effect from equation (15') is:

(A1') $\quad d W^{I}=\sum_{i=1}^{M} \tau_{C_{i}} \frac{d C_{i}}{d \tau_{l k}}+\sum_{j \neq k} \tau_{l j} \frac{d I_{j}}{d \tau_{l k}}-\tau_{L} \frac{\partial l}{\partial \tau_{I k}}$

Like the consumer good tax, the intermediate good tax affects labor supply by increasing the price of consumer goods and by changing the level of government transfers. (A1') is thus equivalent to:

$$
d W^{I}=\sum_{i=1}^{M} \tau_{C i} \frac{d C_{i}}{d \tau_{l k}}+\sum_{j \neq k} \tau_{l j} \frac{d I_{j}}{d \tau_{l k}}-\tau_{L} \sum_{i=1}^{M} \frac{\partial l}{\partial p_{C_{i}}} \frac{I_{i k}}{C_{i}}-\tau_{L} \frac{\partial l}{\partial Y}\left(I_{k}+\sum_{i=1}^{M} \tau_{C i} \frac{\partial C_{i}}{\partial \tau_{l j}}+\sum_{j=1}^{N} \tau_{l j} \frac{\partial I_{j}}{\partial \tau_{l j}}-\tau_{L} \frac{\partial l}{\partial \tau_{l j}}\right)
$$

Substituting equations (A3) through (A6) (which are the same for a tax on an intermediate good as for a tax on a consumer good) into (A2') and rearranging yield

$$
d W^{I}=(\eta-1) \tau_{l k} \frac{d I_{k}}{d \tau_{l j}}+\eta \sum_{i=1}^{M} \tau_{C i} \frac{d C_{i}}{d \tau_{l j}}+\eta \sum_{j \neq k} \tau_{l j} \frac{d I_{j}}{d \tau_{l j}}-\mu\left(\frac{d G}{d \tau_{l j}}-\frac{G I_{k}}{Y}\right)-\mu\left(1-s_{G}\right) I_{k}\left(\frac{\sum_{i=1}^{M} \varepsilon_{C_{k} L} \alpha_{i k}}{\sum_{i=1}^{M} s_{i} \varepsilon_{C_{i} L}}-1\right)
$$

where $\alpha_{i j}=\frac{I_{i j}}{I_{j}}$

\section{Derivation of Equations (24) and (24')}

When the taxed good is an average substitute for leisure, the expression for the tax-interaction effect from (A7) reduces to

$$
d W^{I}=(\eta-1) \tau_{c k} \frac{d C_{k}}{d \tau_{c k}}+\eta \sum_{i \neq k} \tau_{C i} \frac{d C_{i}}{d \tau_{C k}}+\eta \sum_{j=1}^{N} \tau_{l j} \frac{d I_{j}}{d \tau_{c k}}-\mu\left(\frac{d G}{d \tau_{C k}}-\frac{G s_{k}}{p_{C k}}\right)
$$

Expanding the term for the marginal change in government revenue, substituting in the definition of the tax-interaction effect from equation (15) and rearranging yield

$$
d W^{I}=\frac{\eta-1-\mu}{1+\mu} \tau_{c k} \frac{d C_{k}}{d \tau_{C k}}+\frac{\eta}{1+\mu} \sum_{i \neq k} \tau_{C i} \frac{d C_{i}}{d \tau_{C k}}+\frac{\eta}{1+\mu} \sum_{j=1}^{N} \tau_{l j} \frac{d I_{j}}{d \tau_{c k}}-\frac{\mu}{1+\mu} C_{k}\left(1-s_{G}\right)
$$

Substituting (A9) into (15) and canceling terms give

$$
\frac{1}{\lambda} \frac{d U}{d \tau_{C k}}=\frac{\eta}{1+\mu} \tau_{c k} \frac{d C_{k}}{d \tau_{c k}}+\frac{\eta}{1+\mu} \sum_{i \neq k} \tau_{c i} \frac{d C_{i}}{d \tau_{C k}}+\frac{\eta}{1+\mu} \sum_{j=1}^{N} \tau_{I_{j}} \frac{d I_{j}}{d \tau_{C k}}-\frac{\mu}{1+\mu} C_{k}\left(1-s_{G}\right)
$$

Assuming linearity and integrating (A10), collecting terms, and expanding the terms for $\eta$ and $\mu$ yield equation (24).

Following a similar process, starting from equation (A7') instead of (A7), gives equation (24').

Derivation of Equations (25) and (25') 
Starting from equation (A7), assuming that taxes on all other consumption and intermediate goods are zero and that the taxed good is an average substitute for leisure, and expanding the term for the change in government revenue yield

(A11) $\quad d W^{I}=(\eta-1) \tau_{C k} \frac{d C_{k}}{d \tau_{C k}}-\mu\left(\tau_{C k} \frac{d C_{k}}{d \tau_{C k}}+C_{k}+\tau_{L} \frac{d L}{d \tau_{C k}}-\frac{G s k_{k}}{p_{C k}}\right)$

Substituting in $d W^{I}=-\tau_{L} \frac{d l}{d \tau_{C k}}=\tau_{L} \frac{d L}{d \tau_{C k}}$ and rearranging yield

(A12) $\quad d W^{I}=\frac{(\eta-1)}{1+\mu} \tau_{C k} \frac{d C_{k}}{d \tau_{C k}}-\frac{\mu}{1+\mu}\left\lfloor\tau_{C k} \frac{d C_{k}}{d \tau_{C k}}+\left(1-s_{G}\right) C_{k}\right\rfloor$

Substituting (A12) into (15) and rearranging yield

(A13) $\frac{1}{\lambda} \frac{d U}{d \tau_{C k}}=\alpha \tau_{C k} \frac{d C_{k}}{d \tau_{C k}}+\beta\left(\tau_{C k} \frac{d C_{k}}{d \tau_{C k}}+C_{k}\right)$

Integrating (A13) over the change in tax rate and taking a first-order approximation yield equation (25).

A similar process, starting from equation (A7') instead of equation (A7), yields equation (25'). 


\section{Appendix B: The Numerical Model}

Except where otherwise noted, $i$ ranges over primary or intermediate inputs $L, I_{A}, I_{E}, I_{M}$, and $I_{S}$, while the subscript $j$ ranges over produced (intermediate or consumer) goods $I_{A}, I_{E}, I_{M}, I_{S}, C_{B}, C_{F}, C_{M}, C_{S}$, $C_{T}$, and $C_{U}$.

\section{Parameters}

Firm Behavior Parameters

$\alpha_{i j} \quad$ distribution parameter for input $i$ in production of good $j$

$\sigma_{j} \quad$ elasticity of substitution in production of good $j$

\section{Household Behavior Parameters}

$T$ total labor endowment

$\alpha_{l}, \alpha_{C F}, \alpha_{C_{B}} \ldots \alpha_{C_{v}} \quad$ distribution parameters for utility function

$\sigma_{C} \quad$ elasticity of substitution between consumer goods

$\sigma_{U} \quad$ elasticity of substitution between goods and leisure

\section{Government Policy Parameters}

$G \quad$ government spending (transfers to households, in nominal terms)

$\tau_{C B} \ldots \tau_{C U}, \tau_{I A} \ldots \tau_{I S} \quad$ tax rates on consumer and intermediate goods

$\tau_{L} \quad$ tax rate on labor income

\section{Endogenous Variables}

$b_{i j}$

$C_{B}, C_{F}, C_{M}, C_{S}$

$$
C_{T}, \text { and } C_{U}
$$

C

$I_{A}, I_{E}, I_{M}$, and $I_{S}$

$X_{j}$

$L$

$l$

$p_{C}$ use of input $i$ per unit of output of good $j$

aggregate demands for tobacco, food, consumer manufactures, consumer

services,

transportation, and utilities

aggregate demand for composite consumer good

aggregate demand for agriculture, energy, manufactures, and services

aggregate supply of good $j$

aggregate labor supply

leisure or non-market time

price of composite final good 


$\begin{array}{ll}p_{j} & \text { price of good } j \\ R E V & \text { government revenue } \\ U & \text { total consumer utility } \\ X_{i j} & \text { use of good } i \text { in production of good } j\end{array}$

\section{Equations}

Structure of Production

In all industries, output is produced according to:

$$
X_{j}=\left(\sum_{i} \alpha_{i, j} X_{i, j}^{\frac{\sigma_{j}-1}{\sigma_{j}}}\right)^{\frac{\sigma_{j}}{\sigma_{j}-1}}, i=\left\{L, I_{A}, I_{E}, I_{M}, I_{S}\right\}, j=\left\{I_{A}, I_{E}, I_{M}, I_{S}, C_{B}, C_{F}, C_{M}, C_{S}, C_{T}, C_{U}\right\}
$$

Profit for industry $\mathrm{j}$ is given by

$$
\pi_{j}=\left(p_{j}-\tau_{j}\right) X_{j}-\sum_{I} p_{i} X_{i, j}
$$

\section{Optimal Input Intensities}

Differentiating profit with respect to the inputs $X_{i j}$ yields the first order conditions for the optimal input mix:

$$
b_{i j} \equiv \frac{X_{i j}}{X_{j}}=\alpha_{i j}^{\sigma_{j}}\left\{\frac{p_{i}}{p_{j}-\tau_{j}}\right\}^{-\sigma_{j}}
$$

Differentiating profit with respect to output $X_{j}$ gives an equation for the competitive price for each good

$$
p_{j}=\tau_{j}+\sum_{i} b_{i j} p_{i}
$$

Household Utility Function: Labor Supply and Final Good Demands

The representative household's utility function is:

$$
U=U\left(l, C_{B} \ldots C_{U}\right)=\left(\alpha_{l} l^{\frac{\sigma_{u}-1}{\sigma_{u}}}+\alpha_{C} C^{\frac{\sigma_{u}-1}{\sigma_{u}}}\right)^{\frac{\sigma_{u}}{\sigma_{u}-1}}
$$

where $l$ represents leisure and $C$ represents composite consumption:

$$
C=\left(\sum_{j \in B \ldots U} \alpha_{C_{j}} C_{j}^{\frac{\sigma_{c}-1}{\sigma_{c}}}\right)^{\frac{\sigma_{c}}{\sigma_{c}-1}}
$$

The household budget constraint follows

$$
\sum_{j \in B . . U} p_{C_{j}} C_{j}=p_{L} L\left(1-t_{L}\right)+G
$$


where $t_{L}$ is the tax rate on labor income, $T$ is the total time endowment, and $G$ is government spending. The household maximizes utility subject to its budget constraint and the time constraint

(B8) $\quad L=T-l$

This maximization yields the following equations which express the household's behavior:

$$
b_{C_{k}} \equiv \frac{C_{k}}{C}=\left[\alpha_{C_{k}}+\sum_{j \neq k} \alpha_{C_{j}}\left(\frac{\alpha_{C_{k}} p_{C_{j}}}{\alpha_{C_{j}} p_{C_{k}}}\right)^{1-\sigma_{c}}\right]^{\frac{\sigma_{c}}{\sigma_{c}-1}}
$$

(B10) $p_{C}=\sum_{j \in B . . U} p_{C_{j}} b_{C_{j}}$

(B11) $l=\frac{p_{L}\left(1-t_{L}\right) T+G}{p_{L}\left(1-t_{L}\right)+p_{C}\left[\frac{\alpha_{l} p_{C}}{\alpha_{C} p_{L}\left(1-t_{L}\right)}\right]^{-\sigma_{U}}}$

(B12) $C=p_{C}^{-1}\left[p_{L}\left(1-t_{L}\right) L+G\right]$

Combining (B12) with (B9) and (B10) yields the optimal levels of consumption of each good.

\section{Government}

Government revenues finance transfers to households, $G$. The government budget constraint is

(B13) $G=t_{L} L+\sum_{i \in B \ldots U} \tau_{C_{i}} C_{i}+\sum_{i \in A \ldots S} \tau_{I_{i}} I_{i}$

The level of the labor tax is fixed.

Aggregate Demand and Supply

Aggregate demand for the final goods is determined by the household, through equations (B9), (B10), and (B12)

Aggregate demand for labor and for the intermediate goods is determined from the use of each good in production, yielding

(B14) $A D_{i}=\sum_{j} X_{i j}$

Since production of all goods follows constant returns to scale, supplies of both final goods and both intermediate goods are determined by demand. Thus

(B15) $X_{C_{i}}=C_{i}$

(B16) $I_{i}=A D_{I i}$ for $i$ ranging over $D$ and $N$

Solving this last equation simultaneously for all values of $i$ yields aggregate supplies and demands for the intermediate goods. 


\section{Equilibrium Conditions}

The equilibrium conditions are:

(B17) $L=A D_{L}$

and the government budget constraint (B13)

To solve the model, we compute the value of $\tau_{L}$ and the vector of prices that satisfy (B17) and (B13), using $p_{L}$ as the numeraire. By Walras's Law, if one of the two equilibrium conditions holds, the other will also hold, so the vector of primary prices that satisfies (B13) also satisfies (B17).

\section{Benchmark Data}

a) Intermediate Good Production

$\begin{array}{lrrrr} & \text { Energy } & \text { Services } & \text { Agriculture } & \text { Manufactures } \\ \text { Energy } & 253800.3 & 35748.4 & 12135.2 & 83751.8 \\ \text { Services } & 55608.3 & 1182177.2 & 48378.1 & 753981.8 \\ \text { Agriculture } & 174.6 & 109776.9 & 353617.4 & 32591.6 \\ \text { Manufactures } & 108723.6 & 537487.8 & 58516.9 & 2017510.8 \\ \text { Labor } & 79221.2 & 2239303.1 & 55472.4 & 1143765.5 \\ \text { Total } & & & & \\ \text { Production } & 497528.0 & 4104493.4 & 528120.0 & 4031601.6\end{array}$

b) Consumer Good Production

Food, Alcohol Tobacco

\section{Consumer} Services

Energy

Services

Agriculture

Manufactures

Total

Production

$\begin{array}{rrr}297.1 & 0.5 & 34.6 \\ 457622.4 & 22753.2 & 835116.3 \\ 24721.4 & 0.5 & 105.5 \\ 293334.9 & 22096.4 & 75867.5 \\ & & \\ 775975.8 & 44850.6 & 911123.9\end{array}$

$\begin{array}{rr}\text { Transportation } & \text { Utilities } \\ 50320.6 & 55868.1 \\ 92237.5 & 84745.9 \\ 0.5 & 0.5 \\ 0.5 & 553.2 \\ & \\ 142559.1 & 141167.7\end{array}$




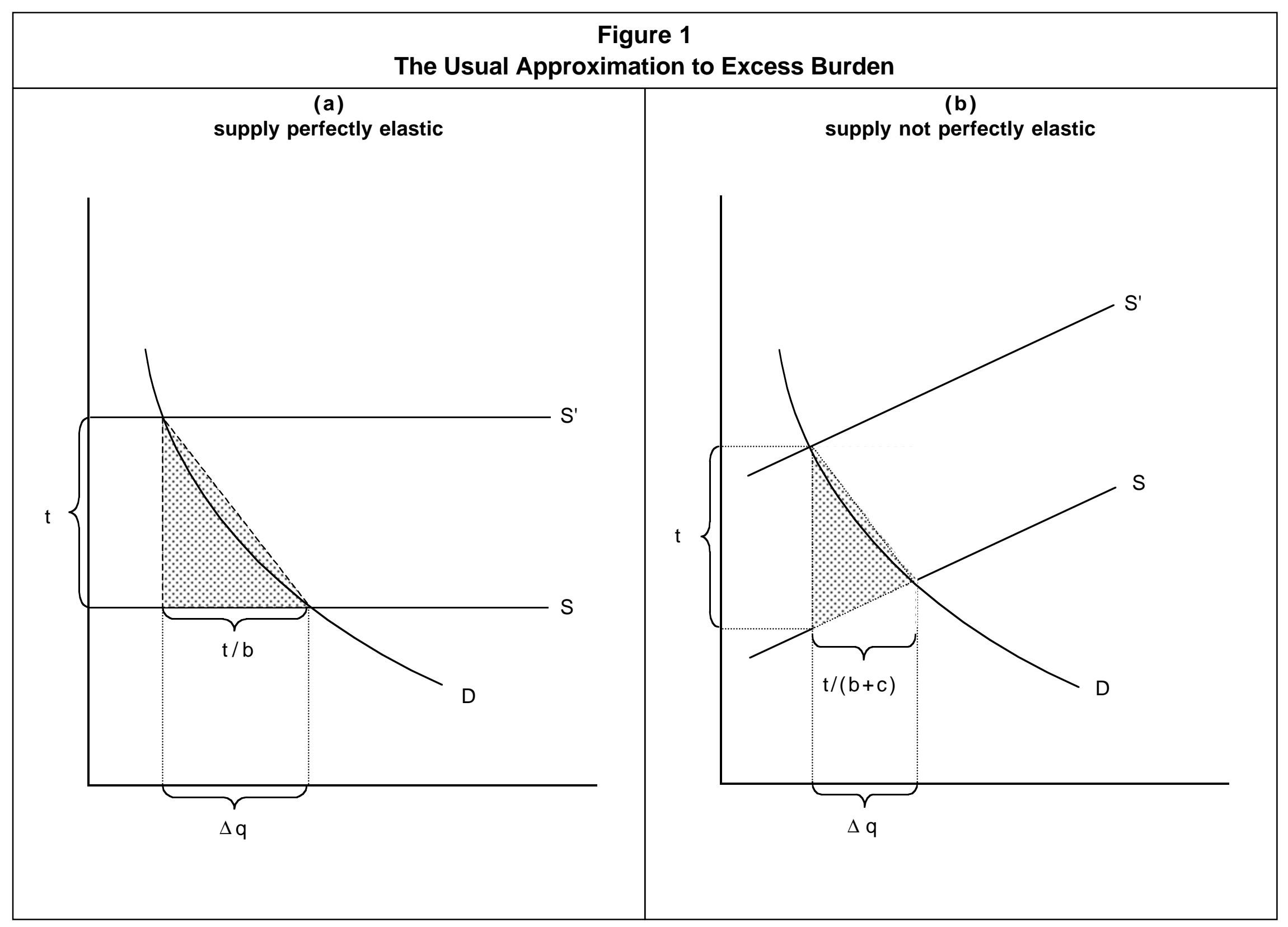


Table 1

Comparison of Excess-Burden Formulas

(Excess Burden in Billions of 1995 dollars)

\begin{tabular}{|c|c|c|c|c|c|c|}
\hline \multirow{2}{*}{\multicolumn{2}{|c|}{ Cigarette Tax }} & \multirow[t]{3}{*}{$\begin{array}{l}\text { "True" } \\
\text { Excess } \\
\text { Burden } \\
\end{array}$} & $\begin{array}{l}\text { Usual } \\
\text { Excess } \\
\text { Burden }\end{array}$ & \multirow[t]{3}{*}{ Error } & \multirow[t]{3}{*}{$\begin{array}{l}\text { Excess } \\
\text { Burden } \\
\end{array}$} & \multirow[t]{3}{*}{ Error } \\
\hline & & & \multirow{2}{*}{$\begin{array}{l}\text { Excess } \\
\text { Burden }\end{array}$} & & & \\
\hline Elasticity & Tax/pack & & & & & \\
\hline \multirow{3}{*}{0.2} & $14.1 \%$ & 0.922 & 0.082 & $-91.1 \%$ & 0.925 & $0.3 \%$ \\
\hline & $31.3 \%$ & 2.173 & 0.375 & $-82.7 \%$ & 2.196 & $1.1 \%$ \\
\hline & $65.3 \%$ & 4.878 & 1.410 & $-71.1 \%$ & 5.032 & $3.2 \%$ \\
\hline \multirow{3}{*}{0.4} & $14.1 \%$ & 0.976 & 0.162 & $-83.4 \%$ & 0.982 & $0.6 \%$ \\
\hline & $31.3 \%$ & 2.401 & 0.727 & $-69.7 \%$ & 2.450 & $2.0 \%$ \\
\hline & $65.3 \%$ & 5.616 & 2.676 & $-52.4 \%$ & 5.943 & $5.8 \%$ \\
\hline \multirow{3}{*}{0.8} & $14.1 \%$ & 1.080 & 0.316 & $-70.7 \%$ & 1.093 & $1.2 \%$ \\
\hline & $31.3 \%$ & 2.803 & 1.378 & $-50.8 \%$ & 2.919 & $4.1 \%$ \\
\hline & $65.3 \%$ & 6.772 & 4.858 & $-28.3 \%$ & 7.514 & $11.0 \%$ \\
\hline \multicolumn{2}{|c|}{ Energy Tax } & & & & & \\
\hline Elasticity & Tax Rate & & & & & \\
\hline \multirow{3}{*}{0.6} & $2.5 \%$ & 1.767 & 0.090 & $-94.9 \%$ & 1.770 & $0.2 \%$ \\
\hline & $5 \%$ & 3.642 & 0.347 & $-90.5 \%$ & 3.661 & $0.5 \%$ \\
\hline & $10 \%$ & 7.653 & 1.295 & $-83.1 \%$ & 7.755 & $1.3 \%$ \\
\hline \multirow{3}{*}{0.9} & $2.5 \%$ & 1.798 & 0.134 & $-92.5 \%$ & 1.803 & $0.3 \%$ \\
\hline & $5 \%$ & 3.760 & 0.517 & $-86.3 \%$ & 3.784 & $0.6 \%$ \\
\hline & $10 \%$ & 8.070 & 1.926 & $-76.1 \%$ & 8.210 & $1.7 \%$ \\
\hline \multirow{3}{*}{1.35} & $2.5 \%$ & 1.844 & 0.200 & $-89.2 \%$ & 1.850 & $0.3 \%$ \\
\hline & $5 \%$ & 3.924 & 0.762 & $-80.6 \%$ & 3.960 & $0.9 \%$ \\
\hline & $10 \%$ & 8.614 & 2.790 & $-67.6 \%$ & 8.832 & $2.5 \%$ \\
\hline
\end{tabular}

Cigarette tax rates are equivalent to $\$ 0.265, \$ 0.59$, and $\$ 1.23$ per pack. 


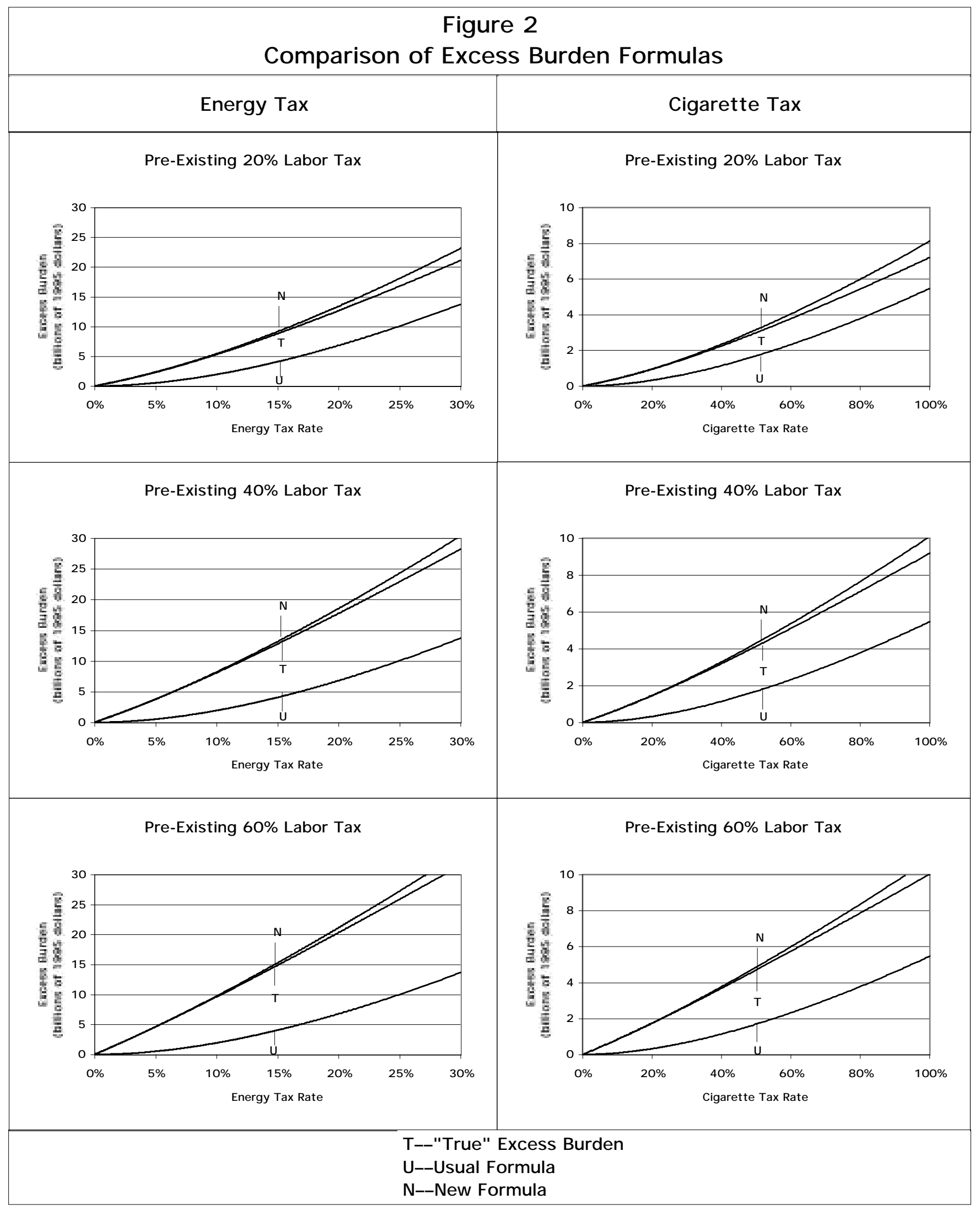

